\title{
Role of CD56 in Normal Kidney Development and Wilms' Tumorigenesis
}

\author{
Li-Wei Yap ${ }^{1,2}$, Jesper Brok ${ }^{2,3}$ and Kathy Pritchard-Jones ${ }^{2}$ \\ ${ }^{1}$ Department of Life Sciences, Imperial College London, London SW7 2AZ, United Kingdom \\ ${ }^{2}$ Cancer Section, UCL Institute of Child Health, University College London, London WC1N 1EH, United Kingdom \\ ${ }^{3}$ Department of Paediatric Haematology and Oncology, Rigshospitalet, Copenhagen University, 2100 Copenhagen, \\ Denmark
}

\begin{abstract}
The cell-surface glycoprotein CD56 has three major isoforms that play important roles in cell adhesion and signalling, which may promote cell proliferation, differentiation, survival, or migration. It is an important molecule in normal kidney development and acts as a key marker in Wilms' tumour stem and progenitor cells. Here, we characterise the structural and genetic features of the CD56 glycoprotein, and examine its the roles in the normal versus diseased metanephric blastema. We reveal areas of CD56-related research that may complement or improve existing Wilms' tumour treatment strategies. A current investigated targeted Wilms' tumour treatment involves the antibody-drug conjugate lorvotuzumab mertansine that binds to CD56, for which a phase II trials was recently initiated.
\end{abstract}

$\begin{array}{ll}\text { ABBREVIATIONS } \\ \text { ALDH: } & \text { Aldehyde Dehydrogenase } \\ \text { CAM: } & \text { Cell Adhesion Molecule } \\ \text { CaMKII: } & \text { Calmodulin-Dependent Kinase II } \\ \text { CD: } & \text { Cluster of Differentiation } \\ \text { DAG: } & \text { Diacylglycerol } \\ \text { ECM: } & \text { Extracellular Matrix } \\ \text { EGFR: } & \text { Epidermal Growth Factor Receptor } \\ \text { EMT: } & \text { Epithelial-to-Mesenchymal Transition } \\ \text { F3: } & \text { Fibronectin type III } \\ \text { FACS: } & \text { Fluorescence Activated Cell Sorting } \\ \text { FAK: } & \text { Focal Adhesion Kinase } \\ \text { FGFR: } & \text { Fibroblast Growth Factor Receptor } \\ \text { FRS-2 } \alpha: & \text { FGFR Substrate-2 } \alpha \\ \text { GPI: } & \text { Glycosylphosphatidylinositol } \\ \text { GRB: } & \text { Growth-Factor Receptor-Bound Protein } \\ \text { HSPG: } & \text { Heparan Sulfate Proteoglycan } \\ \text { Ig: } & \text { Immunoglobulin } \\ \text { IP }: & \text { Inositol Triphosphate } \\ \text { MAPK: } & \text { Mitogen-Activated Protein Kinase } \\ \text { MET: } & \text { Mesenchymal-to-Epithelial Transition } \\ \text { NCAM: } & \text { Neural Cell Adhesion Molecule } \\ \text { NMR: } & \text { Nuclear Magnetic Resonance } \\ \text { PAPR: } & \text { Poly ADP-Ribose Polymerase } \\ \text { PI3K: } & \text { Phosphatidylinositol 3-Kinase } \\ \text { PIP }: & \text { Phosphatidylinositol Biphosphate } \\ \text { PKC: } & \text { Protein Kinase C } \\ \text { PLC } \gamma: & \text { Phospholipase C- } \gamma \\ \text { RPTP } \alpha: & \text { Receptor Protein Tyrosine Phosphatase- } \alpha \\ \text { RT-PCR: } & \text { Reverse Transcription-Polymerase Chain Reaction } \\ \text { SH: } & \text { Src Homology } \\ \text { SOS: } & \text { Son of Sevenless } \\ \text { SPR: } & \text { Surface Plasmon Resonance } \\ \text { VGFR: } & \text { Vascular Endothelial Growth Factor Receptor } \\ & \\ & \end{array}$




\section{Introduction}

CD56, or Neural Cell Adhesion Molecule-1 (NCAM-1), is a cell-surface glycoprotein expressed early in development by various cell types [1,2]. CD56 molecules on adjacent cells adhere mainly to one another, but can be activated by other signaling molecules (e.g. ECM components, and cellsurface receptors) [2-4]. CD56 influences cell migration, proliferation, differentiation, apoptosis, and more specifically kidney organogenesis $[\mathbf{2 , 5 , 6 ]}$. Unfortunately, CD56 might also be essential for Wilms' tumor (WT), as WT originates from the abnormal development of the metanephric blastema, and studies ranging from Fluorescence Assisted Cell Sorting (FACS) immuno-sorting to clonogenicity assays demonstrate the blastemal localization of CD56 [7,8].

Here, we review the structural and genetic features of CD56, its functions in normal kidney development and possible roles in WT, as well as novel treatment strategies targeting CD56. Although overall WT survival rates have risen to $90 \%$ over the last four decades, the mortality rate is near 50\% for patients who relapse. If effective, CD56-specific treatments could in theory improve survival rates and reduce complementary treatment burden (chemotherapy and radiotherapy) and the adjacent risk of significant side effects [9].

\section{Methods}

We searched (Sept. 2015) the NCBI database PubMed for recent research articles, using key words like 'CD56', 'Wilms' tumor' or 'nephroblastoma', 'oncogenesis', and 'kidney development'. To get a more comprehensive review, we also screened for additional relevant references in the identified publications. This meant researching the older citations relevant to CD56 in the newer publications. In total, 96 relevant publications were identified, of which 63 were included in this review.

\section{The Three Major CD56 Isoforms}

CD56 has at least 24 isoforms generated by alternative splicing, three of which are considered major: CD56-120kDa, CD56-140kDa and CD56-180kDa [2,10] (Fig. 1). Here, the molecular weight refers to their non-glycosylated and non-sialylated forms [11]. It is unknown if alternative splicing is triggered by differential selection of splice or polyadenylation sites [12], or exactly which biochemical factors regulate it. CD56-120kDa is the most common isoform in normal adult kidney tissue, whereas CD56-140kDa is the salient isoform in embryonic development, CD56 ${ }^{+}$ malignancies, and tumor cell lines [2,13] (Table 1). In other words, CD56-140kDa and CD56$180 \mathrm{kDa}$ are expressed during kidney organogenesis, before expression switches to CD56-120kDa in the later stages of Mesenchymal-to-Epithelial Transition (MET) as the kidney becomes developed [14].

The major isoforms share a constant $\mathrm{N}$-terminal ectodomain, comprising five contiguous $\mathrm{C} 2$-type immunoglobulin (Ig)-like domains, and two fibronectin type III-like (F3) domains [15-17] (Fig. 2 and 3). However, they interact differently with the cell surface. Whilst CD56-120kDa is linked to the plasma membrane via a glycosylphosphatidylinositol (GPI) anchor and lacks a cytoplasmic domain, the other two major isoforms have a single transmembrane domain with cytoplasmic tails of different lengths [2]. Additionally, the carbohydrate component of CD56 comprises N-linked glycans, with those in Ig-5 tagged with polymers of eight to $100 \alpha(2,8)$-linked sialic acid residues $[\mathbf{1 4 , 1 8 , 1 9 ]}$. The poly(sialic acid) chains are shorter in CD56-120kDa [14].

\section{Cell-Cell and Cell-Matrix Adhesive Properties Of CD56}

CD56 mediates cell-cell adhesion via homophilic interactions (Fig. 4). As determined by Nuclear Magnetic Resonance (NMR), CD56 molecules on the same cell aggregate, via ionic and hydrophobic interactions between Ig-1 and Ig-2, to form cis-dimers [20-22]. Then, cis-dimers on adjacent cells cross-link via trans-homophilic anti-parallel interactions between Ig-1 and Ig-3 in a 
zipper-resembling formation, reducing steric hindrance between the apposing plasma membranes [22-24]. The homophilic interactions are stronger in the embryonic isoforms than in the adult isoform, because their shorter poly(sialic acid) chains cause the ectodomains to be less negatively charged. This lowers electrostatic repulsion between adjacent CD56 molecules [25,26]. In addition, electron microscopy highlighted a kink of $90^{\circ}$ to $110^{\circ}$ between Ig-4 and Ig-5. This regulates the extent of homophilic interactions [22,27].

CD56 also facilitates cell-matrix interactions, since Ig-1 and $\mathrm{Ig}-2$ form ionic interactions with heparan sulfate proteoglycans (HSPGs), as determined by site-directed mutagenesis [21,28,29]. Since the HSPG-binding sites overlap with the site for homophilic binding to other CD56 molecules, CD56 can take part in homophilic and heterophilic binding to different ligands simultaneously [21,29]. In fact, heterophilic binding to HSPGs induces a conformational change in CD56 that improves its affinity for homophilic binding [30]! Interaction with HSPGs also makes it possible for CD56 to bind indirectly to collagen I for even stronger cell-matrix adhesion [21]. However, there exist exceptions, in which certain HSPGs weaken the homophilic interactions of CD56 and in turn cell-cell adhesion [31].

\section{CD56 Signalling Pathways}

CD56 activation leads to the assembly of a signaling complex for several pathways (Fig. 5). Since CD56-120kDa lacks a cytosolic domain, it is mainly involved in cell adhesion, as it cannot bind to intracellular signaling proteins and transduce signals on its own. However, if CD56-120kDa forms part of a complex, it may still participate in signal transduction. CD56 also initiates different signaling pathways, depending on whether it is localized in lipid rafts. For instance, CD56-140kDa outside lipid rafts activates FGFR-1 [4], whereas CD56-140kDa in lipid rafts activates p59 ${ }^{\text {Fyn}}$; mutation of palmitoylation sites on CD56 or lipid raft destruction prevents p59 ${ }^{\text {Fyn }}$ activation [32,33]. Here, we summarize a few important signaling pathways mediated by CD56.

\section{CD56-FGFR-1 Signalling Pathways}

As determined by NMR and Surface Plasmon Resonance (SPR), the formation of a zipper-like assembly by homophilic interactions creates high-affinity binding sites between F3-1 and F3-2 for FGFR-1 [31]. Triple immunofluorescence staining showed that this brings the intracellular Tyrkinase domains of two adjacent FGFR-1 molecules into close mutual proximity for transautophosphorylation and downstream signaling [20]. The presence of poly(sialic acid) further strengthens the interaction of CD56 with FGFR-1. Phosphoproteomics showed that poly(sialic acid) promotes cell migration via the activation of FGFR-1 and MAPK ERK1/2 [34].

The intracellular signaling proteins activated by FGFR-1 following transautophosphorylation include phospholipase C- $\gamma$ (PLC $\gamma$ ) and Fibroblast Growth Factor Receptor Substrate-2 $\alpha$ (FRS-2 $\alpha$ ) [35]. PLC $\gamma$ hydrolyses $\mathrm{PI}(4,5) \mathrm{P}_{2}$ to form $\mathrm{I}(1,4,5) \mathrm{P}_{3}$ and $1,2-\mathrm{DAG} . \mathrm{I}(1,4,5) \mathrm{P}_{3}$ causes an increase in the cytosolic concentration of $\mathrm{Ca}^{2+}$, which activates calmodulin and in turn Calmodulin-Dependent Kinase II (CaMKII) [17,36]. Meanwhile, 1,2-DAG either activates Protein Kinase C (PKC) or is converted to arachidonic acid [4]. Both CaMKII and PKC drive cell proliferation or differentiation. In addition, PLC $\gamma$ activates Src kinase, causing cytoskeletal changes and subsequently cell migration [35].

Meanwhile, FRS-2 $\alpha$ is constitutively bound to the intracellular juxtamembrane domain of FGFR1. It activates the MAPK ERK1/2 signaling pathway by recruiting GRB2 and SOS [37], further driving cell proliferation or differentiation. FRS-2 $\alpha$ also activates Phosphoinositol 3-Kinase (PI3K), which promotes Akt-mediated cell survival [35]. The involvement of these proteins was proven by CD56 inducing sustained phosphorylation of FRS-2 $\alpha$, Akt and Src, as well as temporary phosphorylation of ERK1/2 [37]. In addition, the MAPK ERK1/2 signaling pathway leads to the inside-out activation of $\beta 1$-integrin, thus influencing cell-matrix adhesion [4].

\section{CD56-p59Fyn Signaling Pathways}


The cytosolic tail of CD56-140kDa and CD56-180kDa binds directly to both regulatory and nonreceptor Tyr-kinases. These include the cytosolic Src-family Tyr-kinase p59 ${ }^{\mathrm{Fyn}}$, which activates Focal Adhesion Kinases (FAKs) to allow integrin-mediated cytoskeletal rearrangements and cell spreading [28,38]. Clustering of CD56 (in lipid rafts) maximizes p59 $9^{\text {Fyn }}$ activation, since p59 Fyn showed no visible increase in phosphorylation in the presence of antibodies [39]. Ironically, another possible mechanism of $\mathrm{p} 59^{\mathrm{Fyn}}$ activation is dephosphorylation by Receptor Protein Tyrosine Phosphatase- $\alpha$ (RPTP $\alpha)$, which is recruited by CD56 [39,40]. This was confirmed by coimmunoprecipitation [33]. Table 2 summarizes the interactions of each domain in CD56.

\section{CD56 Localization in Normal Kidney Development}

CD56 drives MET in early kidney development. CD56 up-regulation in the pre-induced metanephric mesenchyme coincides with Wolffian duct enlargement and ureteric bud formation around the fifth week of gestation [6]. It continues in the condensing cap mesenchyme following induction by the ureteric bud [41,42]; conversely, the ureteric bud shows no CD56 expression [43]. During MET, the cap mesenchyme differentiates into the metanephric blastema for further differentiation into polarized epithelia [3]. However, Northern blot analysis demonstrated that CD56 expression decreases gradually as the fetal kidney matures (Fig. 6 and 7) [44]. Nonetheless, CD56 expression continues in the nephrogenic aggregates and, to a smaller extent, the cap mesenchyme [41]. CD56 is also still present in the C- and S-shaped bodies [42,44]. The cap mesenchymal cells exhibit CD56 down-regulation once the tip of the Wolffian duct has extended past them; unfortunately, the mechanism by which CD56 down-regulation occurs is yet to be determined [41].

Once a fully polarized epithelium has been formed, the epithelium as well as mature mesonephric tubules stains negatively for CD56 $[\mathbf{4 4 , 4 5}]$. In metanephric blastemal cells that do not epithelialize, CD56 may remain expressed throughout embryonic development but its expression is fully terminated at the end of the perinatal period [44], and in normal adult kidneys, CD56 is expressed only by renal nerves and rare interstitial cells with dendritic morphology in the corticomedullary junction [3]. This is corroborated by microarray analysis comparing human fetal and adult kidneys, where CD56 showed greater difference in expression (23-fold less in adult kidneys) than other cellsurface markers [46].

Most of the metanephric blastemal cells undergo one last round of differentiation and nephron formation just before the metanephros reaches maturity [47]. Hence, in the normal mature kidney, there is comparatively little metanephric blastema remaining [48], Unfortunately, in rare occasions, it is from here that WT may arise, usually in early childhood. Importantly, the CD56 ${ }^{+}$cells in the kidneys are not all the same, thus forming a heterogeneous population of stem and more committed progenitor cells. miRNA and epigenetic analysis proved that some $\mathrm{CD}^{+} 6^{+}$cells in normal kidney tissue undergo Epithelial-to-Mesenchymal Transition (EMT) rather than MET [46]. As demonstrated by immunofluorescent staining, the $\mathrm{CD}^{+} 6^{+}$cell population are also positive for the mesenchymal markers [49] vimentin and N-cadherin [17] but negative for the epithelial marker [49] E-cadherin, yet the stem or progenitor activity is solely contained in the CD56 ${ }^{+}$cells [46].

\section{CD56 Localization in Wilms' Tumor}

Early histological studies showed numerous elements in WT, such as epithelia, that are otherwise found during early normal kidney development. This suggests that WT has an embryonic nature, and it was proposed that the WT blastema contains an early pluripotent stem cells $[\mathbf{7 , 5 0 , 5 1 ]}$. It was discovered that the aberrant metanephric blastemal cells attempt to undergo MET but do not differentiate past the early embryonic stage $[\mathbf{7 , 8 , 5 0 ]}$.

WT CD $56^{+}$cells have a greater potential to proliferate and form tumors than WT CD56 cells. As real-time RT-PCR analysis showed, WT CD56 ${ }^{+}$cells over-express a set of proteins that confers 'stem-ness' and is required for WT propagation, including WT1, SIX2, OCT4, and NANOG. WT 
$\mathrm{CD} 6^{+}$cells also exhibit high vimentin expression and low E-cadherin expression, which are characteristics of aberrant metanephric blastemal cells [8,9].

The blastema also shows a concomitant phenotype of CD56-positivity and EpCAM-negativity [43,52]. Recalling that $\mathrm{CD}^{+} 6^{+}$cells are heterogeneous, it is thought that $\mathrm{CD}^{2} 6^{+} \mathrm{EpCAM}^{+} \mathrm{FZD}^{+}$ cells represent true stem cells, whereas $\mathrm{CD}^{-} 6^{+} \mathrm{EpCAM}^{-} \mathrm{FZD7}^{+}$cells are arrested at a more committed renal progenitor state [43]. In contrast, WT epithelial cells, which show a concomitant phenotype of CD56-negativity and EpCAM-positivity, exhibit down-regulation of the 'stem-ness' proteins [52]. This further suggests that CD56 might play significant roles in WT onset. However, an immuno-staining experiment conducted in 2014 showed that CD56 is not solely a WT blastemal marker. In an immuno-staining experiment conducted last year, CD56 stained the epithelial and stromal components of WT more frequently than two other putative markers (CITED1 and SIX1), and the blastemal components less frequently [53].

CD56 might play a significant role in WT diagnosis, given that it is also a marker in other forms of cancers in the nervous, immune, and neuroendocrine systems. In fact, CD56 over-expression correlates with tumor aggression and higher mortality rates in some cancer types [2]. More recently, quantitative RT-PCR showed that the more committed progenitor cells are rich in not only CD56 but also ALDH-1. Indeed, these $\mathrm{CD} 56^{+} \mathrm{ALDH}-1^{+}$cells exhibit higher expression of E-cadherin and SIX2 and lower expression of vimentin than true WT stem cells, which were identified by their lower ALDH-1 expression. Perhaps the most relevant discovery was that these CD56 ${ }^{+} \mathrm{ALDH}-1^{+}$ cells could dedifferentiate in vitro to form true WT stem cells, which implicates dedifferentiation as a possible mechanism in generating the WT blastema [54]. In addition, these cells are negative in the hematopoietic stem cell marker CD133 [55]. Quantitative PCR analysis showed up-regulation of renal progenitor (e.g. WT1, SIX2, OSR1, SALL1, PAX2, CITED1) and stem-ness genes (e.g. OCT4, NANOG, KLF4, LIN28A) [56].

\section{Roles of CD56 in Normal Kidney Development and Wilms' Tumor}

During early normal kidney development and MET, the high CD56 expression, coupled with the large initial presence of its embryonic isoforms, ensures significant activation of p59 ${ }^{\text {Fyn }}$ and FAKs. This not only mediates integrin-binding but also activates the MAPK ERK1/2 and PI3K/Akt signaling pathways, thus promoting cell proliferation and survival respectively [9,50]. Therefore, the metanephric blastema expands and differentiates into epithelia. The binding of FAKs to integrin may also facilitate migration of the epithelial cells for recruitment into the epithelium by the ureteric bud.

As the kidney becomes gradually developed, CD56 expression switches to the 120-kDa isoform [14], which lacks a cytosolic domain to activate p59 Fyn or FAKs. Perhaps then the ability of CD56$120 \mathrm{kDa}$ to form stronger cell-cell interactions in the epithelium, due to their shorter poly(sialic acid) chains, takes precedence, permitting maintenance of epithelial integrity. However, in WT, CD56 expression switches back to the 140-kDa isoform [14], and CD56 down-regulation is reversed [57]. As $\mathrm{p} 59^{\mathrm{Fyn}}$ and FAKs are re-activated, the MAPK ERK1/2 and PI3K/Akt signaling pathways that promote cell proliferation and survival are triggered, reversing or blocking MET and causing tumorigenesis. In addition, the longer poly(sialic acid) chains on CD56-140kDa weaken cell-cell adhesion due to increased electrostatic repulsion, increasing the likelihood of EMT and metastasis of cells from the tumor $[\mathbf{1 7 , 2 6 ]}$.

Although FGFR-1 has been implicated in normal kidney development, it is unknown whether it could be activated by CD56 to promote WT. FGFR-1 is expressed mainly in metanephric blastemal cell lineages [35], increasing its likelihood of co-localization with CD56. If CD56-FGFR-1 signaling pathways exist in WT blastemal cells, they could enhance the enlargement of the WT blastema and promote the dedifferentiation of more committed WT progenitor cells into WT stem cells via EMT.

Finally, although CD56 mediates cell-matrix adhesion, WT blastema shows an almost complete lack of ECM proteins. This is consistent with the production of an incomplete ECM when normal 
tissue becomes cancerous, which allows more space in the kidney tissue for WT blastemal cells to invade [58]. Around the very early stages of MET (before the differentiation of the WT blastemal cells is arrested), the metanephric mesenchyme slowly loses its original ECM containing fibronectin and collagens I and III due to cap condensation, allowing a new basement membrane to be synthesized in place [59]. Fibronectin loss is in fact synchronized with the initial CD56 upregulation to ensure stronger cell-cell adhesion during MET [44].

Nevertheless, cancer cells that undergo metastasis and migrate still have to pass through the normal matrix secreted by adjacent non-cancerous cells. To facilitate this passage, the $\alpha 3$ and $\alpha 6$ integrin subunits, which are indirectly activated by CD56, bind to fibronectin and laminin in the interstitial and basal membranes [58]. Thereafter, since metastasis is not driven by CD56-mediated inside-out signaling [4], perhaps it is promoted by the reduced affinity of CD56 homophilic binding and in turn cell-cell adhesion as a result of longer poly(sialic acid) chains on CD56-140kDa.

Upon binding to HSPGs, CD56 undergoes a conformational change for stronger cis-homophilic interactions and in turn cell-cell adhesion. Hence, the absence of HSPGs in the extracellular milieu of the WT blastema results in weaker cell-cell adhesion, further blocking MET and promoting EMT. Then, in the later stages of WT, when the cancer cells have migrated from the WT blastema to the basement membrane of the kidney and angiogenesis has occurred, the interaction between CD56 and HSPGs might promote metastasis by allowing cancer cells to bind to the vascular endothelium and undergo extravasation. Moreover, HSPGs in the basement membrane may concentrate growth factors like EGF and FGF, which might be necessary for the proliferation and migration of cancer cells [28].

\section{Clinical Applications}

Despite the excellent overall survival (approx. 90\%) for WT, almost 15\% of patients relapse, usually within two years of diagnosis. WT subgroups with high-risk tumor histopathology (blastemal or diffuse anaplasia) and metastatic disease are of the highest risk. Even with optimized treatment of surgery, radiotherapy, and chemotherapy, sometimes including high-dose chemotherapy with stem-cell rescue therapy, more than one third of all relapsed patients do not survive [60]. Hence, with our increased understanding of the pathways and driver mutations involved in WT tumorigenesis comes the push to identify and add targeted therapy.

In the modern clinical setting, WT patients with a second relapse or refractory disease may be enrolled in early phase trials. However, the promising results seen in the laboratory of targeted therapy have not yet translated into a clinical difference. Challenges in testing targeted therapy include the scarcity of patients with refractory or relapsed disease, the rapid progression of relapse, and the genetic heterogeneity of WT.

Currently, studies recruiting children with pediatric solid tumors and WT are mushrooming. Ongoing early phase trials assessing targeted therapies include the EGFR inhibitor erlotinib, the VEGFR inhibitor ramucirumab, the PARP inhibitor talazoparib, and the exportin inhibitor selinexor. One interesting class of immuno-targeted therapy comprises antibody-drug conjugates targeting CD56 expressed on WT metanephric blastema [51]. These include IMGN901 (lovotuzumab), which is a conjugate between a humanized monoclonal antibody (huN901) that binds to CD56, and a maytansinoid (DM1) that inhibits the cell division cycle of excessively promoting tumor cells [61]. First-time lorvotuzumab testing on two WT models induced complete anti-tumor responses [62]. In May 2015, a phase II trial was initiated by the American National Cancer Institute and Children's Oncology Group. More than 10 WT patients have been recruited but the results are pending [63]. In theory, the effectiveness of lorvotuzumab depends on the extent of CD56 expression, which varies due to the genetic heterogeneity of WTs displaying different proportions of blastemal elements $[\mathbf{9 , 4 7 ]}$. However, as predominant blastemal histopathologies have a poorer prognosis, lorvotuzumab may be relatively most beneficial in this subtype of WT.

Meanwhile, there is ongoing work to profile the genes that might confer the self-renewing property of the $\mathrm{CD} 56^{+} \mathrm{ALDH}-1^{+}$stem cells [47]. Already, the patterns of changes in CD56 
expression have been found to be very similar to those of topoisomerase-2A, indicating the possible susceptibility of WT stem cells to topoisomerase inhibitors, with irinotecan, although being a topoisomerase-1 inhibitors being a potential intervention for relapse patients [8]. Another area of current research aims to find the cell (type) of origin of WT, which has not been pinpointed despite the identification of $\mathrm{CD} 56^{+} \mathrm{ALDH}-1^{+}$cells as WT stem cells [51].

\section{Conclusion}

CD56 is a glycoprotein involved in normal kidney development and a marker in WT. Further research is needed to fully understand its genetic features and its function in normal versus diseased blastemal development. CD56 targeted therapy is currently undergoing early phase testing for WT and other childhood cancers.

\section{Conflict of interest}

The authors report no conflicts of interest. The authors alone are responsible for the content and writing of the article.

\section{Acknowledgements}

This research was supported by the Imperial College London Department of Life Science UROP bursary. We also thank Neil Sebire and Will Mifsud for helpful discussions.

\section{References}

[1] Hirsch M, Gaugler L, Deagostini-Bazin H, Bally-Cuif L, Goridis C. Identification of Positive and Negative Regulatory Elements Governing Cell-Type-Specific Expression of the Neural Cell Adhesion Molecule Gene. Mol. Cell Biol. 1990;10(5):1959-1968.

[2] Gattenloehner S, Stuehmer T, Leich E, Reinhard M, Etschmann B, Voelker H, et al. Specific Detection of CD56 (NCAM) Isoforms for the Identification of Aggressive Malignant Neoplasms with Progressive Development. Am. J. Pathol. 2009;174(4):1160-1171.

[3] Markovic-Lipkovski J, Mueller CA, Klein G, Flad T, Klatt T, Blaschke S, et al. Neural cell adhesion molecule expression on renal interstitial cells. Nephrol. Dial. Transplant. 2007;22(6):1558-1566.

[4] Kren A. The role of NCAM signaling and its effector protein, b1-integrin, in tumor progression. University of Basel; 2006.

[5] Paratcha G, Ledda F, Ibanez CF. The Neural Cell Adhesion Molecule NCAM Is an Alternative Signaling Receptor for GDNF Family Ligands. Cell 2003;113(7):867-879.

[6] Schell C, Wannera N, Hubera TB. Glomerular development - Shaping the multi-cellular filtration unit. Semin. Cell Dev. Biol. 2014;36(1):39-49.

[7] Aiden AP, Rivera MN, Rheinbay E, Ku M, Coffman EJ, Truong TT, et al. Wilms Tumor Chromatin Profiles Highlight Stem Cell Properties and a Renal Developmental Network. Cell Stem Cell 2010;6(6):591-602.

[8] Pode-Shakked N, Metsuyanim S, Rom-Gross E, Mor Y, Fridman E, Goldstein I, et al. Developmental tumourigenesis: NCAM as a putative marker for the malignant renal stem/progenitor cell population. J. Cell Mol. Med. 2009;13(8B):1792-1808.

[9] Pode-Shakked N, Shukrun R, Mark-Danieli M, Tsvetkov P, Bahar S, Pri-Chen S, et al. The isolation and characterization of renal cancer initiating cells from human Wilms' tumour xenografts unveils new therapeutic targets. EMBO Mol. Med. 2013;5(1):18-37.

[10] Knowles DM editor. Neoplastic Haematopathology. 2nd ed.: Lippincott Williams \& Wilkins; 2001.

[11] Santoni MJ, Barthels D, Vopper G, Boned A, Goridis C, Wille W. Differential exon usage involving an unusual splicing mechanism generates at least eight types of NCAM cDNA in mouse brain. EMBO J. 1989;8(2):385-392.

[12] Walsh FS, Dickson G. Generation of Multiple N-CAM Polypeptides from a Single Gene. BioEssays 1989;11(4):83-88.

[13] Lanier LL, Testi R, Bindl J, Phillips JH. IDENTITY OF Leu-19 (CD56) Leukocyte Differentiation Antigen and Neural Cell Adhesion Molecule. J. Exp. Med. 1989;169(6):2233-2238.

[14] Roth J, Zuber C, Wagner P, Taatjes DJ, Weisgerber C, Heitz PU, et al. Reexpression of poly(sialic acid) units of the neural cell adhesion molecule in Wilms tumor. Proc. Natl. Acad. Sci. USA 1988;85(9):2999-3003.

[15] Goridis C, Brunet J. NCAM: structural diversity, function and regulation of expression. Semin. Cell Biol. 1992;3(3):189-197. 
[16] Becker JW, Erickson HP, Hoffman S, Cunningham BA, Edelman GM. Topology of cell adhesion molecules. Proc. Natl. Acad. Sci. USA 1989;86(3):1088-92.

[17] Cavallaro U, Niedermeyer J, Fuxa M, Christofori G. N-CAM modulates tumour-cell adhesion to matrix by inducing FGF-receptor signalling. Nat. Cell Biol. 2001;3(7):650-657.

[18] Seidenfaden R, Krauter A, Schertzinger F, Gerardy-Schahn R, Hildebrandt H. Polysialic Acid Directs Tumor Cell Growth by Controlling Heterophilic Neural Cell Adhesion Molecule Interactions. Mol. Cell. Biol. 2003;23(16):5908-5918.

[19] Brady S, Siegel G, Albers RW, Price D editors. Basic Neurochemistry: Principles of Molecular, Cellular and Medical Neurobiology. 8th ed.: Academic Press; 2011.

[20] Kochoyan A, Poulsen FM, Berezin V, Bock E, Kiselyov VV. Structural basis for the activation of FGFR by NCAM. Protein Sci. 2008;17(10):1698-1705.

[21] Kiselyov VV, Berezin V, Maar TE, Soroka V, Edvardsen K, Schousboe A, et al. The First Immunoglobulin-like Neural Cell Adhesion Molecule (NCAM) Domain Is Involved in Double-reciprocal Interaction with the Second Immunoglobulin-like NCAM Domain and in Heparin Binding. J. Biol. Chem. 1997;272(15):10125-10134.

[22] Soroka V, Kolkova K, Kastrup JS, Diederichs K, Breed J, Kiselyov VV, et al. Structure and Interactions of NCAM Ig1-2-3 Suggest a Novel Zipper Mechanism for Homophilic Adhesion. Structure 2003;11(10):1291-1301.

[23] Ćirović S, Vještica J, Mueller CA, Tatić S, Vasiljević J, Milenković S, et al. NCAM and FGFR1 coexpression and colocalization in renal tumors. Int. J. Clin. Exp. Pathol. 2014;7(4):1402-1414.

[24] Kos FJ, Chin CS. Costimulation of T cell receptor-triggered IL-2 production by Jurkat T cells via fibroblast growth factor receptor 1 upon its engagement by CD56. Immunol. Cell Biol. 2002;80(4):364-369.

[25] Nybroe O, Moran N, Bock E. Equilibrium Binding Analysis of Neural Cell Adhesion Molecule Binding to Heparin. J. Neurochem. 1989;52(6):1947-1949.

[26] Fuster MM, Esko JD. The Sweet and Sour of Cancer: Glycans as Novel Therapeutic Targets. Nat. Rev. Cancer 2005;5(7):526-542.

[27] Hall AK, Rutishauser U. Visualization of Neural Cell Adhesion Molecule by Electron Microscopy. J. Cell Biol. 1987;104(6):1579-1586.

[28] Zocchi MR, Ferrero E, Toninelli E, Castellani P, Poggi A, Rugarli C. Expression of N-CAM by human renal cell carcinomas correlates with growth rate and adhesive properties. Exp. Cell Res. 1994;214(2):499-509.

[29] Reyes AA, Akeson R, Brezina L, Cole GJ. Structural requirements for neural cell adhesion molecule-heparin interaction. Cell Regul. 1990;1(8):567-576.

[30] Kallapur SG, Akeson RA. The Neural Cell Adhesion Molecule (NCAM) Heparin Binding Domain Binds to Cell Surface Heparan Sulfate Proteoglycans. J. Neurosci. Res. 1992;33(4):538-548.

[31] Berezin V editor. Structure and Function of the Neural Cell Adhesion Molecule NCAM. 1st ed.: Springer Science \& Business Media; 2010.

[32] Lehembre F, Yilmaz M, Wicki A, Schomber T, Strittmatter K, Ziegler D, et al. NCAM-induced focal adhesion assembly: a functional switch upon loss of E-cadherin. EMBO J. 2008;27(19):2603-2615.

[33] Bodrikov V, Leshchyns'ka I, Sytnyk V, Overvoorde J, den Hertog J, Schachner M. RPTPalpha is essential for NCAM-mediated p59yn activation and neurite elongation. J. Cell Biol. 2005;168(1):127-139.

[34] Li J, Dai G, Cheng Y, Qi X, Geng M. Polysialylation promotes NCAM-mediated cell migration in an FGFRdependent manner, but independent of adhesion capability. Glycobiology 2011;21(8):1010-1018.

[35] Bates CM. Role of fibroblast growth factor receptor signaling in kidney development. Am. J. Physiol. Renal Physiol. 2011;301(2):F245-F251.

[36] Alberts B. Molecular biology of the cell. 5th ed. New York: Garland Science; 2008.

[37] Francavilla C, Cattaneo P, Berezin V, Bock E, Ami D, de Marco A, et al. The binding of NCAM to FGFR1 induces a specific cellular response mediated by receptor trafficking. J. Cell Biol. 2009;187(7):1101-1116.

[38] Lamouille S, Xu J, Derynck R. Molecular mechanisms of epithelial-mesenchymal transition. Nat. Rev. Mol. Cell Biol. 15;15(3):178-196.

[39] Beggs HE, Baragona SC, Hemperly JJ, Maness PF. NCAM140 Interacts with the Focal Adhesion Kinase p125 fak and the SRC-related Tyrosine Kinase p59 fyn . J. Biol. Chem. 1997;272(13):8310-8319.

[40] Nielsen J, Gotfryd K, Li S, Kulahin N, Soroka V, Rasmussen KK, et al. Role of Glial Cell Line-Derived Neurotrophic Factor (GDNF)-Neural Cell Adhesion Molecule (NCAM) Interactions in Induction of Neurite Outgrowth and Identification of a Binding Site for NCAM in the Heel Region of GDNF. J. Neurosci. 2009;29(36):11360-11376.

[41] Bard JBL, Gordon A, Sharp L, Sellers WI. Early nephron formation in the developing mouse kidney. J. Anat. 2001;199(4):385-392.

[42] Nouwen EJ, Dauwe S, van der Biest I, de Broe ME. Stage- and segment-specific expression of cell-adhesion molecules N-CAM, A-CAM, and L-CAM in the kidney. Kidney Int. 1993;44(1):147-158.

[43] Metsuyanim S, Harari-Steinberg O, Buzhor E, Omer D, Pode-Shakked N, Ben-Hur H, et al. Expression of Stem Cell Markers in the Human Fetal Kidney. PLoS One 2009;4(8):e6709.

[44] Klein G, Langegger M, Goridis C, Ekblom P. Neural cell adhesion molecules during embryonic induction and development of the kidney. Development 1988;102(4):749-761. 
[45] Crossin KL, Chuong C, Edelman GM. Expression sequences of cell adhesion molecules. Proc. Natl. Acad. Sci. USA 1985;82(20):6942-6946.

[46] Harari-Steinberg O, Metsuyanim S, Omer D, Gnatek Y, Gershon R, Pri-Chen S, et al. Identification of human nephron progenitors capable of generation of kidney structures and functional repair of chronic renal disease. EMBO Mol. Med. 2013;5(10):1556-1568.

[47] Li Y, Wingert RA. Regenerative medicine for the kidney: stem cell prospects \& challenges. Clin. Transl. Med. 2013;2(1):11.

[48] Sariola H, Saarma M. GDNF and its receptors in the regulation of the ureteric branching. Int. J. Dev. Biol. 1999;43(5):413-418.

[49] Zhao Q, Caballero OL, Davis ID, Jonasch E, Tamboli P, Yung WKA, et al. Tumor-specific isoform switch of the fibroblast growth factor receptor 2 underlies the mesenchymal and malignant phenotypes of clear cell renal cell carcinomas. Clin. Cancer Res. 2013;19(9):2460-2472.

[50] Williamson KA, van Heyningen V. Towards an understanding of Wilms' tumour. Int. J. Exp. Pathol. 1994;75(3):147-155.

[51] Hohenstein P. The stem and roots of Wilms' tumours. EMBO Mol. Med. 2013;5(1):4-6.

[52] Schacker MA. Selection of Wilms' tumour blastemal cells and their maintenance in vitro by Wnt signalling pathway inhibition. 2014

[53] Sehic D, Ciornei CD, Gisselsson D. Evaluation of CITED1, SIX1, and CD56 Protein Expression for Identification of Blastemal Elements in Wilms Tumor. Am. J. Clin. Pathol. 2014;141(6):828-833.

[54] Shukrun R, Pode-Shakked N, Pleniceanu O, Omer D, Vax E, Peer E, et al. Wilms' Tumor Blastemal Stem Cells Dedifferentiate to Propagate the Tumor Bulk. Stem Cell Reports 2014;3(1):24-33.

[55] Dziedzic K, Pleniceanu O, Dekel B. Kidney stem cells in development, regeneration and cancer. Semin Cell Dev Biol 2014;36:57-65.

[56] Pode-Shakked N, Pleniceanu O, Gershon R, Shukrun R, Kanter I, Bucris E, et al. Dissecting Stages of Human Kidney Development and Tumorigenesis with Surface Markers Affords Simple Prospective Purification of Nephron Stem Cells. Sci Rep 2016;6:23562.

[57] Edelman GM, Crossin KL. Cell Adhesion Molecules: Implications for a Molecular Histology. Annu. Rev. Biochem. 1991;60(1):155-190.

[58] Peringa J, Molenaar WM, Timens W. Integrins and extracellular matrix-proteins in the different components of the Wilms' tumour. Virchows Arch. 1994;425(2):113-119.

[59] Ekblom P, Vestweber D, Kemler R. Cell-Matrix Interactions and Cell Adhesion During Development. Annu. Rev. Biochem. 1986;2(1):27-47.

[60] Ha TC, Spreafico F, Graf N, Dallorso S, Dome JS, Malogolowkin M, et al. An international strategy to determine the role of high dose therapy in recurrent Wilms' tumour. Eur J Cancer 2013;49(1):194-210.

[61] Wood AC, Maris JM, Gorlick R, Kolb EA, Keir ST, Reynolds CP, et al. Initial Testing (Stage 1) of the AntibodyMaytansinoid Conjugate, IMGN901 (Lorvotuzumab Mertansine), by the Pediatric Preclinical Testing Program. Paediatr. Blood Cancer 2013;60(11):1860-1867.

[62] Geller JI, Hohenstein P. Molecular-Targeted Therapy for Pediatric Renal Tumors. In: Pritchard-Jones K, Dome JS, editors. Renal Tumors of Childhood: Biology and Therapy. 1st ed.: Springer-Verlag Berlin Heidelberg; 2015. p. 165-184.

[63] Children's Oncology Group, National Cancer Institute. Lorvotuzumab Mertansine in Treating Younger Patients With Relapsed or Refractory Wilms Tumor, Rhadomyosarcoma, Neuroblastoma, Pleuropulmonary Blastoma, Malignant Peripheral Nerve Sheath Tumor, or Synovial Sarcoma. 2015;NCT02452554.

[64] Rivera MN, Haber DA. Wilms' Tumour: Connecting Tumorigenesis and Organ Development in The Kidney. Nat. Rev. Cancer 5 (2005), 699-712.

[65] UniProtKB. (7 September 2016) UniProtKB - Pl3591 (NCAM1_HUMAN). Available from: http://www.uniprot.org/uniprot/P13591 [Accessed 1 October 2016]. 


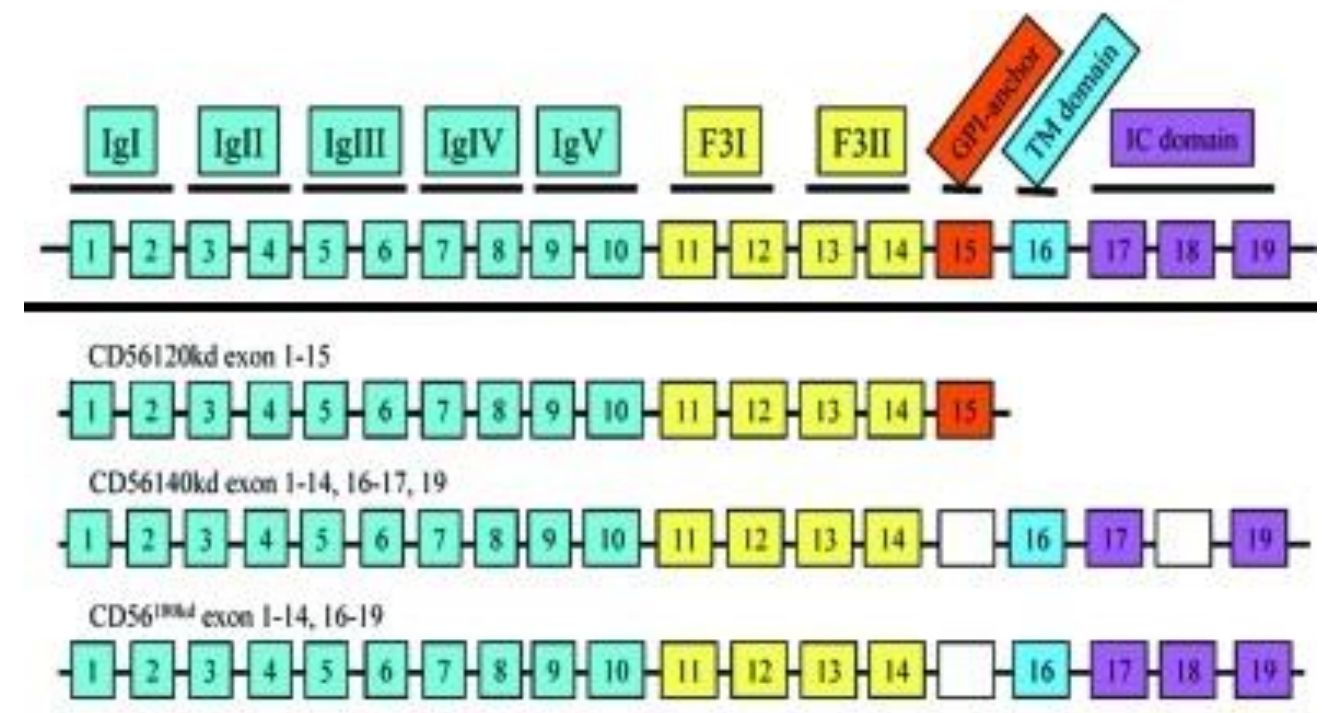

Fig. 1. Alternative splicing of exons in CD56 gene to give the three major isoforms (Figure modified from [2]). 


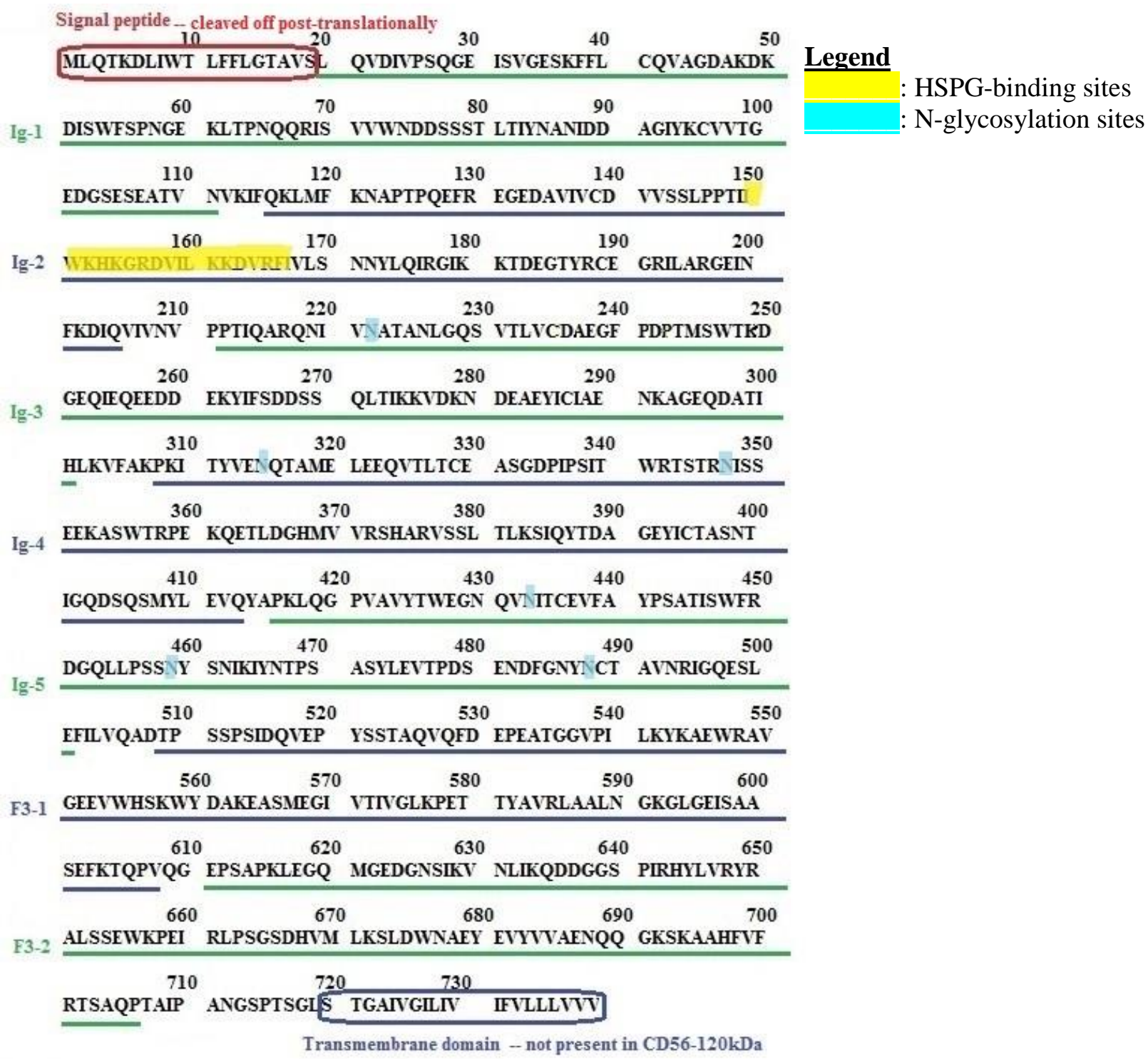

Fig. 2. Canonical amino acid sequence of shared N-terminus of major CD56 isoforms. Key amino acid residues whose positions have been identified are highlighted. (Figure modified from UniProtKB database Accession No. P13591 [65]) 


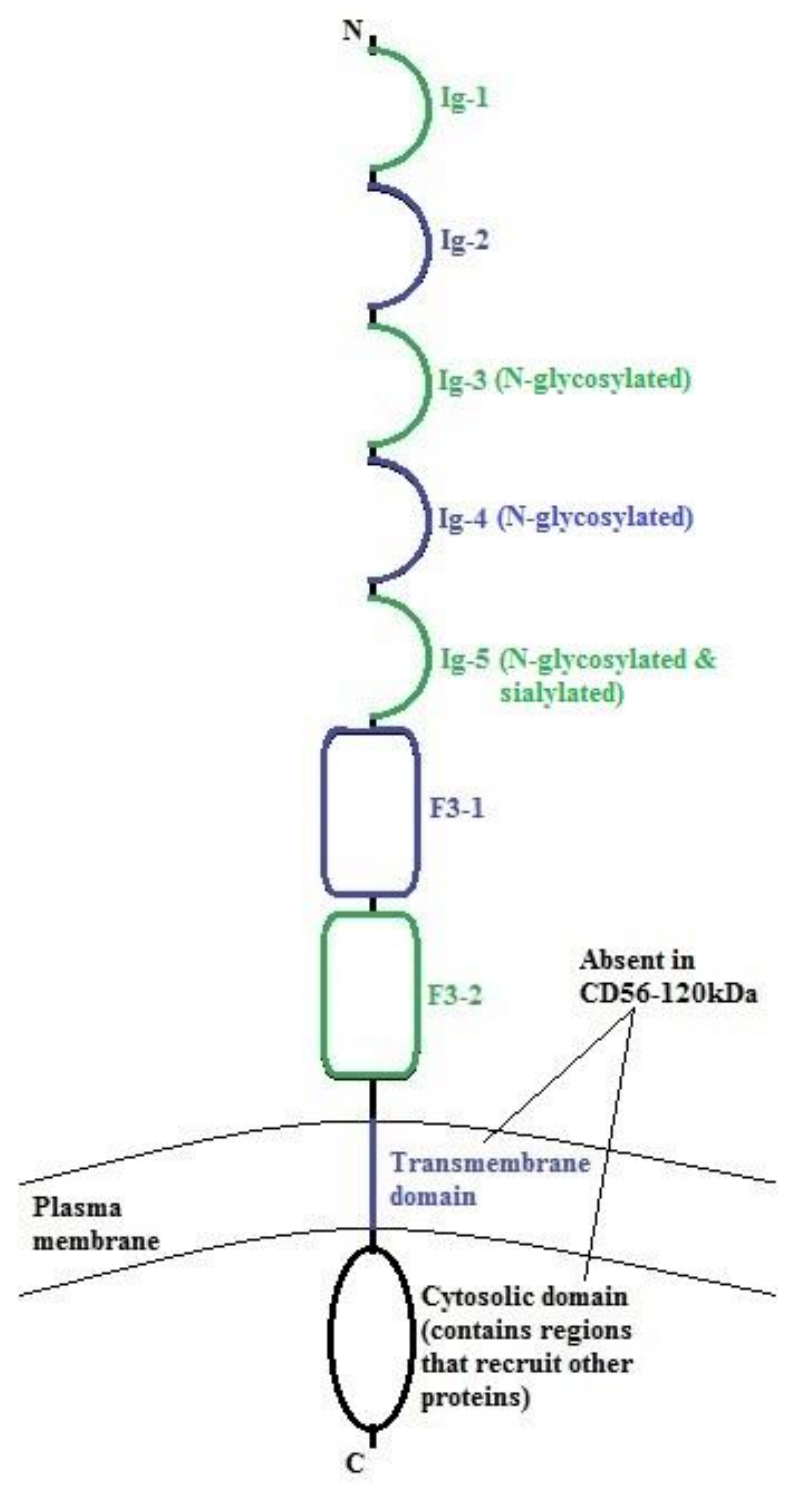

Fig. 3. Arrangement of Ig-like and F3 domains in CD56 ectodomain. CD56-120kDa contains a GPI anchor in place of the transmembrane and cytosolic domains. 


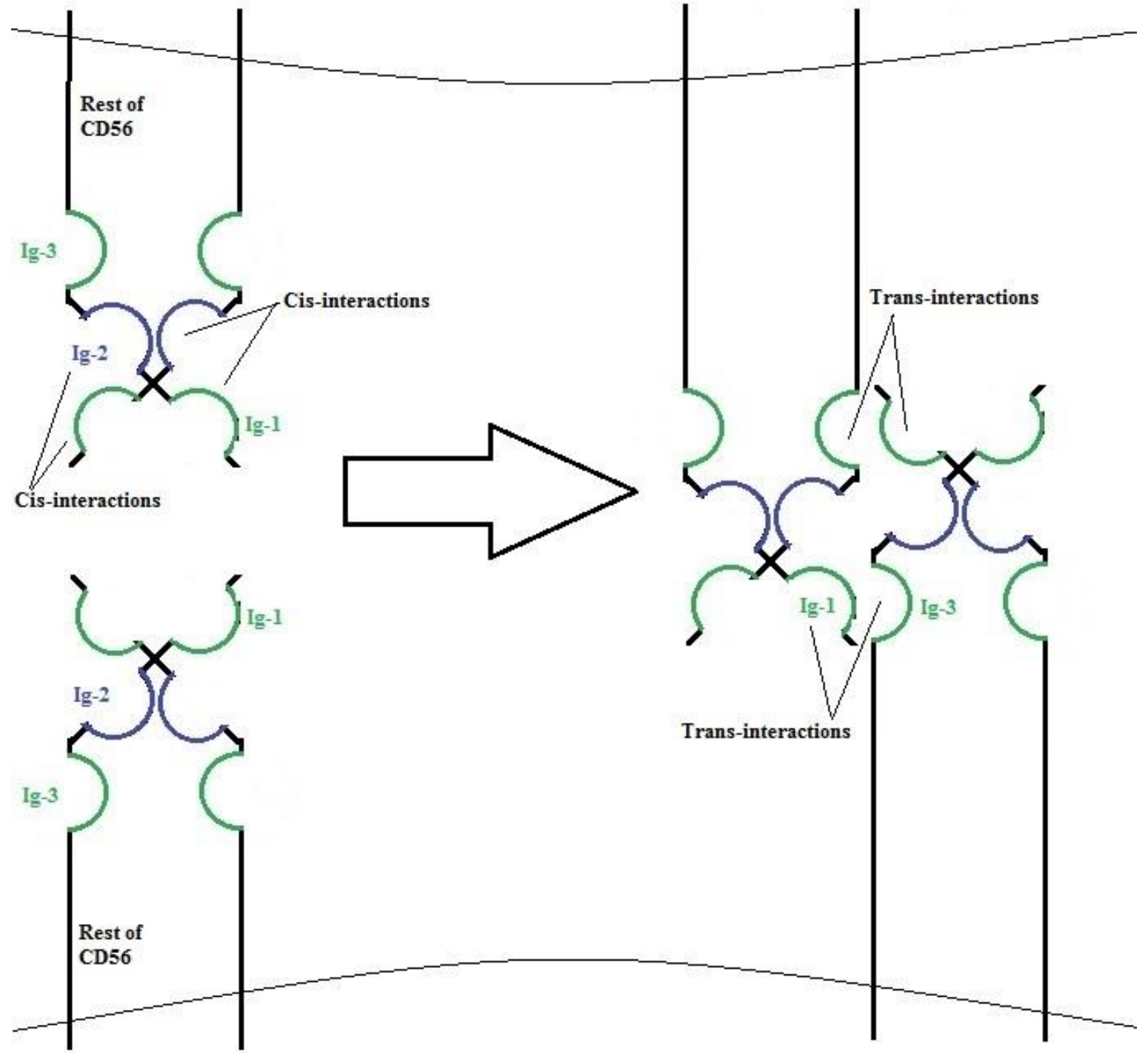

Fig. 4. Cell-cell adhesion is mediated first by cis-homophilic interactions between individual CD56 molecules on the same cell, which then allow the formation of trans-homophilic interactions between CD56 cis-dimers on adjacent cells. The domains that belong to the same CD56 monomer on the left are labelled accordingly. Cis-interactions are formed between Ig-1 and Ig-2, whereas trans-interactions are formed between Ig-1 and Ig-3. 


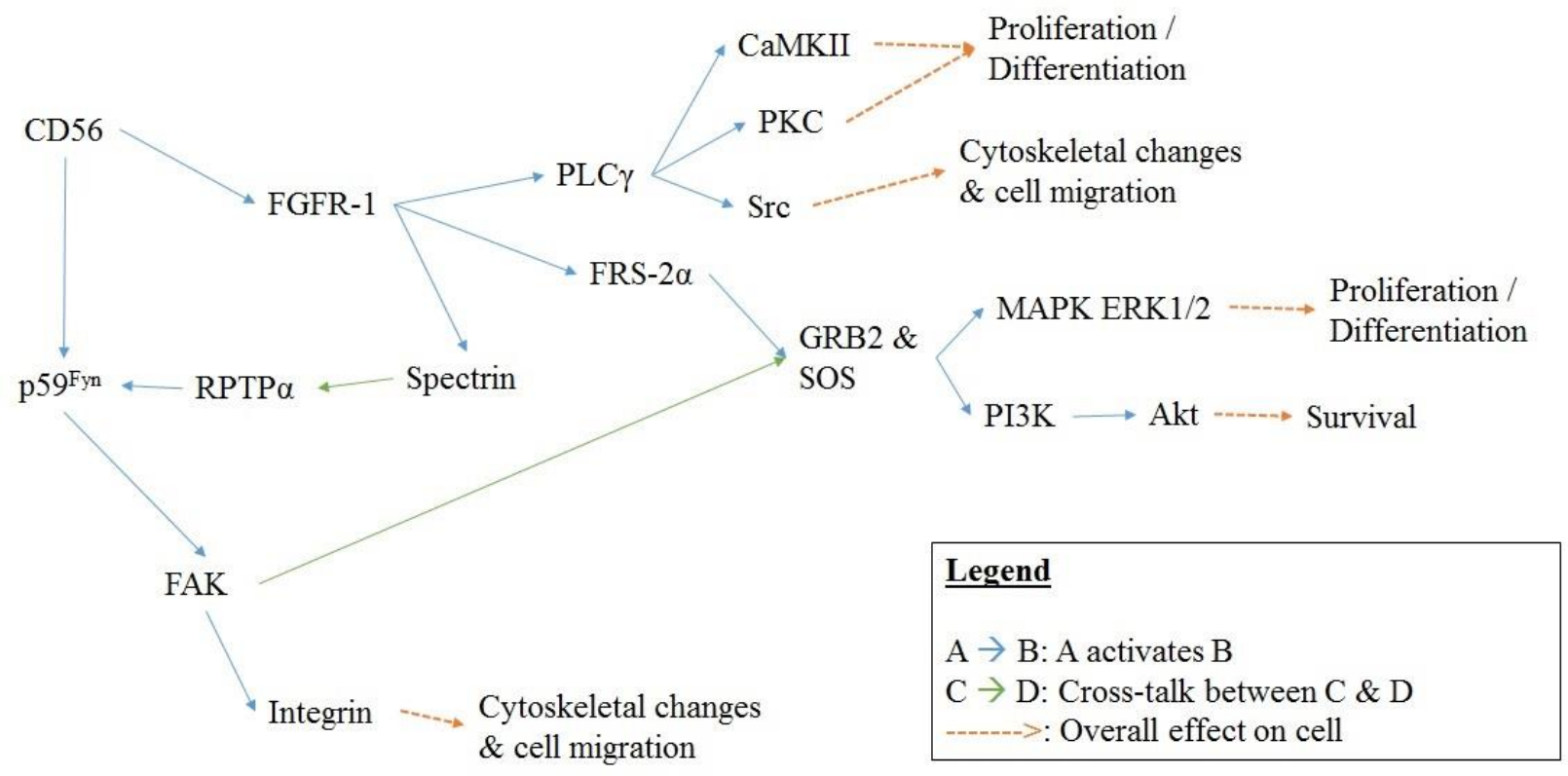

Fig. 5. CD56 mediates multiple signalling pathways by binding to FGFR-1 and p59 ${ }^{\text {Fyn }}$, leading to profound effects on the cell. 


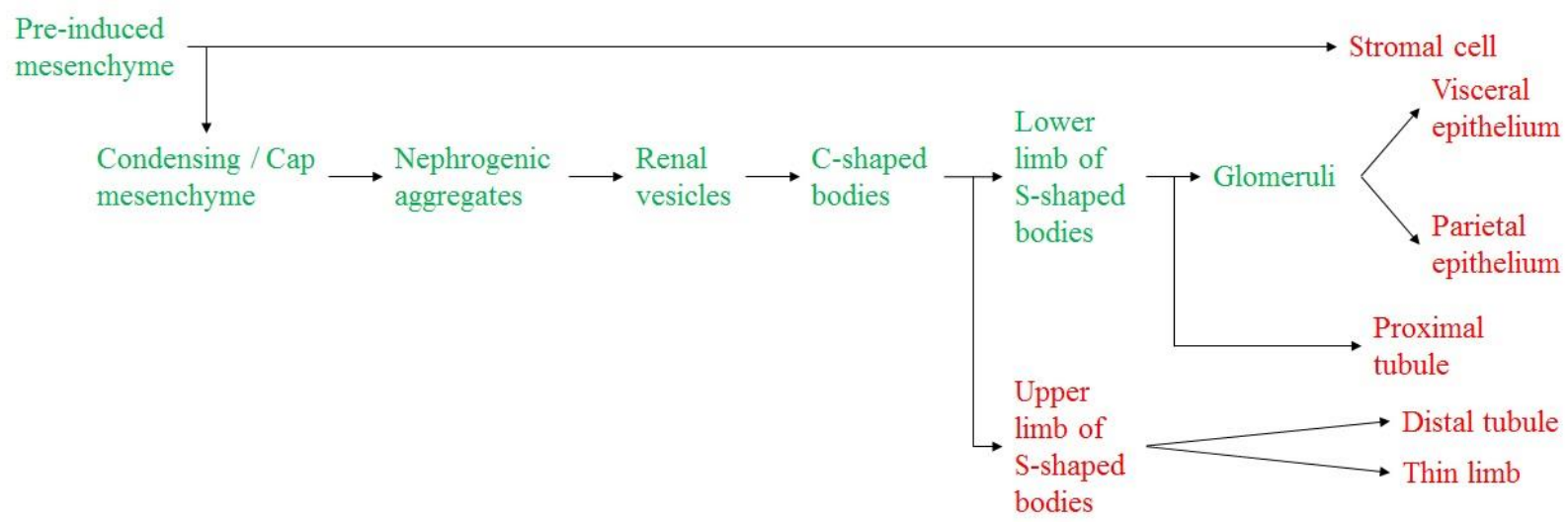

Fig. 6. CD56 staining at various stages of kidney development. The tissues highlighted in green exhibit high CD56 expression, whereas the tissues highlighted in red exhibit low CD56 expression. Evidently, CD56 expression decreases as the kidney gradually matures. (Figure modified from [42]) 

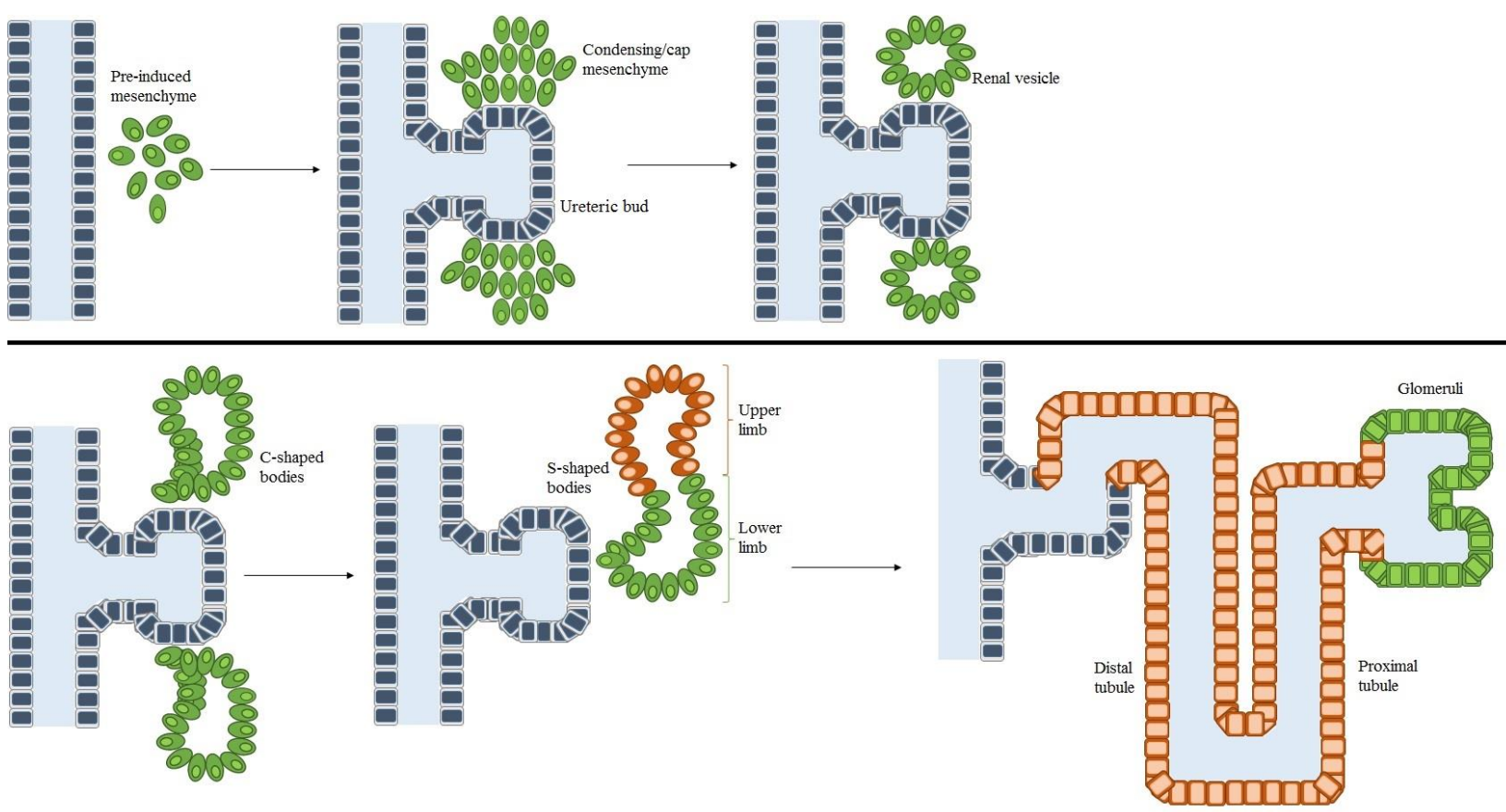

Fig. 7. A diagrammatic representation of Fig. 6. The pre-induced mesenchyme, cap mesenchyme, renal vesicle, C-shaped bodies and glomeruli (highlighted in green) exhibit high CD56 expression, whereas the proximal and distal convoluted tubules (highlighted in red) exhibit low CD56 expression. Evidently, CD56 expression decreases as the kidney gradually matures. Note that adult glomeruli do not express CD56. (Figure modified from [64]) 
Table 1. Differences Between Major CD56 Isoforms

\begin{tabular}{|l|l|}
\hline CD56-120kDa & CD56-140kDa / CD56-180kDa \\
\hline No intracellular domain; GPI anchor linked to & Intracellular domain present; no GPI anchor; \\
extracellular monolayer of plasma membrane & single transmembrane domain \\
\hline More common in normal cells & More common in diseased cells \\
\hline Shorter poly(sialic acid) chains & Longer poly(sialic acid) chains \\
\hline Mainly expressed in adult tissue & Mainly expressed in embryonic development \\
\hline
\end{tabular}


Table 2. What macromolecules do the domains in CD56 bind to?

\begin{tabular}{|l|l|}
\hline Ig-1 & Cis- and trans-homophilic CD56 interactions; HSPGs \\
\hline Ig-2 & Cis-homophilic CD56 interactions; HSPGs \\
\hline Ig-3 & Trans-homophilic CD56 interactions \\
\hline Ig-4 & - \\
\hline Ig-5 & Does not bind other macromolecules directly but can influence binding affinity, as it \\
\hline F3-1 & FGFR-1 \\
\hline F3-2 & FGFR-1 \\
\hline Cytosolic & p59Fyn \\
tail & \\
\hline
\end{tabular}

